\title{
Las sexualidades y su capital espacial. Exploraciones teórico-situadas en la ciudad intermedia de Bahía Blanca, Argentina
}

Larreche, José Ignacio

Doctorando en Geografía, Departamento de Geografía y Turismo, Universidad Nacional del Sur, CONICET Bahía Blanca, Argentina. Becario del CONICET. Miembro del grupo Género y Feminismos. joseilarreche@gmail.com.

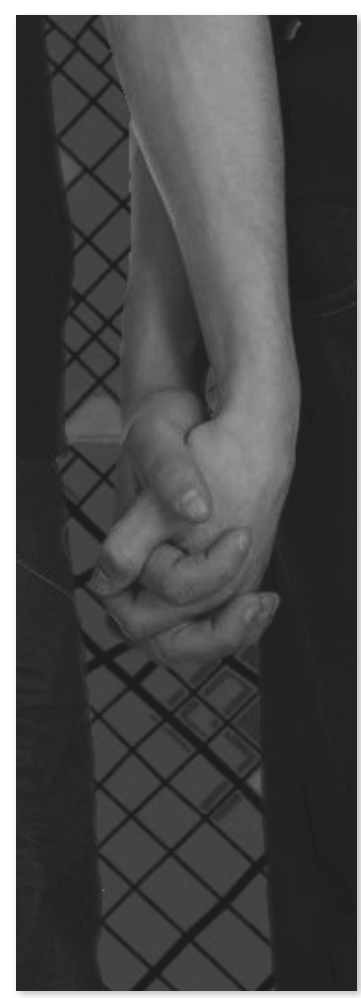

http://dx.doi.org/10.30972/crn.25253515 ISNN 1666-6186. Volumen 25 N. 25 (Noviembre de 2018) Pp. 163-183 - Recibido: 01-03-18. Aprobado: 30-10-18 


\title{
Resumen
}

En Argentina, la Geografía es una ciencia con pocas teorizaciones acerca de la dimensión espacial de la sexualidad, a pesar de ser un terreno fecundo para otras ciencias sociales. El estudio parte de concebir al espacio exterior como regulador de la alteridad mediante mecanismos de control que imprimen una jerarquía social y, por ende, espacial. En Bahía Blanca, la condición sexodiversa aún reviste un carácter de estigma que dificulta alcances performativos. Mediante entrevistas y la observación participante, se señalarán los intersticios sociosexuales en la ciudad vinculados con el juego interescalar, los ritmos diurnos-nocturnos y la virtualidad de las socializaciones. El objetivo que se persigue es interpelar dicho espacio a partir de vivencias de sujetos autodefinidos gais en un intento de, por un lado, explorar el grado de plenitud de estas prácticas socioespaciales y, por el otro, potenciar las herramientas que aporta la geografía para alumbrar estas experiencias situadas.

\section{Palabras clave}

Geografía de las sexualidades; sujetos autodefinidos gais; posibilidades espaciales; ciudad intermedia de Bahía Blanca.

\begin{abstract}
Sexuality and its spatial capital exploring their theoretical-locational expfessions in the middle-sized city of Bahía Blanca, Argentina.

Geography is a science with few theories about the spatial dimension of sexuality at a national level, although this has been a fertile ground for other social sciences. Understanding public space as an otherness regulator, through mechanisms of control that imprint a spatial social hierarchy. In Bahía Blanca, alternative sexual practices still carry a stigma that hinders performative acts. Through flexible interviews and participant observation, the social space of these self-defined gay subjects is discussed, considering the sociosexual interstices linked to these practices, their day-night rhythms and the virtuality of these socializations. The goal is to question this space on the basis of the experiences of people self-defined as gay in an attempt, on the one hand, to explore the degree of fulfilment of these socio-spatial practices, and on the other hand, improve the tools provided by geography to better illuminate these locational experiences.
\end{abstract}

\section{Keywords}

Geography of Sexualities; self-defined gay subjects; spatial possibilities, Intermediate city of Bahía Blanca. 


\section{Introducción ${ }^{1}$}

La presente investigación se desprende de una línea reciente denominada Geografía de las Sexualidades (BRowne ET ÁL., 2009). Esta se inicia entre la década de 1980 y 1990, como parte del eco académico de los primeros movimientos de liberación gay y lesbiana (santos, 2016). Las características de las sociedades contemporáneas y el peso que van adquiriendo los asuntos de diversidad en ellas (SABSAY, 2011) ponen en relieve una retroalimentación, no siempre lineal ni armónica, de un triple nexo entre sociedad, entendida como un conjunto de instituciones que regulan las normas sociales; un grupo social específico, en este caso el colectivo gay y el quehacer estatal como corolario de la relación entre las dos anteriores, a partir de políticas públicas específicas. Para el análisis y la problematización de la dimensión sexual del territorio, se acudirá a la teoría (micro) sociológica de Goffman (1970) en diálogo con posicionamientos de autores que han remarcado el marco espacial del espectro sociosexual (Leroy 2005; González Pérez 2014; Domínguez Bobadilla, 2013). En esta dirección, se planteará la discusión de un concepto neurálgico del corpus de la geografía, como el de ciudad intermedia partiendo de interrogar ¿qué actos performativos se dan en aglomerados urbanos intermedios o pequeños?, ¿qué grado de amplitud ostentan las prácticas cotidianas de sujetos autodefinidos como gais? ¿Y cómo sortean las restricciones impuestas en su ciudad de residencia? El cruce con la antropológica y sociología, provocado por el giro cultural (Lindón y HiernauX, 2010), dará punteos preliminares.

La investigación exploratoria responde a un enfoque cualitativo, basado en entrevistas abiertas a un total de diez sujetos autodefinidos gais de diverso rango etario, y la observación participante, sustanciada en espacios y escenarios diversos como plazas y parques, "previas" ${ }^{2}$, fiestas y aplicaciones de citas. Dichas fuentes estuvieron mediadas por una fuerte implicación (Blanco, 2014), ya que la obtención de los testimonios requirió complicidad y confianza. Como consecuencia, el estudio repara en una actitud comprensiva y comprometida de la geografía social (HeRIN, 2006) tomando como insumo las valoraciones que describen vivencias en Bahía Blanca (figura 1). Conocer el espacio vivido a escala urbana, el peso de las representaciones y sus itinerarios resultantes constituye el principal objetivo de la investigación. En este sentido, desandar los meandros espaciales de sujetos identificados como gais en función de sus percepciones apalabradas es, de algún modo, apropiarnos de sus experiencias.
1. La presente pesquisa se desarrolló en la fase inicial de los interrogantes suscitados en el proceso de investigación doctoral, orientados a desentrañar el espacio social de la ciudad intermedia de Bahía Blanca, desde los atributos de sexo-género.

2. Las "previas" en Argentina refieren a reuniones informales en casas o bares, $y$ sirven de acondicionamiento y preparación antes de arribar a un recinto de mayor jerarquía para el consumo de divertimento nocturno. El espacio es compartido con amistades y allegados, y durante el tiempo de la "previa" se consumen bebidas alcohólicas en un marco ambientado con música o juegos entre los participantes. 
3. La obra que sienta las bases de este campo del conocimiento es la de BELL Y VALENTINE (1995) Mapping Desire: Geographies of Sexualities, a pesar de que antes se habían llevado a cabo trabajos más aislados, como el de LAURIA Y KNOPP (1985).

4. Se establecerá una distinción entre espacio y espacialidad que consideramos pertinente. El espacio conforma un fenómeno material, remite a una idea de construcción social en tanto espacio habitado; la espacialidad se debe interpretar como la aprehensión humana de ese espacio, donde se solapan deseos e intenciones; espacios más imaginarios que concretos.

Figura 1. Área de estudio. Fuente: LARRECHE, 2018

\section{Un territorio sin explorar: geografía de las sexualidades}

La Geografía de las Sexualidades se posiciona como un campo de investigación fértil en la década de 1990, a pesar de que con anterioridad antropólogos, sociólogos y estudiosos de la cultura abordaron la cuestión colateralmente (BRownE ET ÁL., 2009), como parte del eco académico de los movi- mientos de liberación gay y lesbiana (SANTos, 2016). Geógrafos y geógrafas con casas editoriales en Londres y Nueva York ${ }^{3}$ fueron pioneros en llevar adelante un trabajo deliberado en torno a la problematización de los efectos que suscitan la sexualidad, las prácticas específicas (en función de una subjetividad sexual) y las espacialidades ${ }^{4}$. Continuaron acrecentando el cúmulo de investigaciones pensadores británicos (BINNIE, 1997; HubBard, 1999; Brown, 2001), y en el siglo XXI aparecieron los primeros aportes desde España y Francia (SANTos, 2003; LERoY, 2005; JaURAND, 2011). Asimismo, es preciso mencionar otros antecedentes que nutrieron a estas geografías sin haber estado encolumnados en la temática. Algunos compilados cruciales en la consolidación de este camino son el capítulo que CASTELLS (1983) le dedicó a la construcción social del barrio gay de El Castro; EtTorre (1978), al analizar los movimientos feministas en torno al gueto lésbico y la sección dedicada a los cuerpos y el deseo en Las Otras Geografías, de Nogué y Romero (2006), a pesar de que esta última ya se circunscribe en medio de un gran número de iniciativas con esta tónica.

Estas referencias reportan una clara juventud en la ciencia geográfica, dado que la sexualidad ha representado un tabú cognitivo siendo un tema "incómodo" en determinadas instituciones académicas, justificado por un cierto temor de las y los 
autores por ser identificados con aquellas orientaciones sexuales sobre las que investigan (SANTos, 2016). Como resultado, se invisibilizó o subestimó a la sexualidad como objeto de estudio geográfico ${ }^{5}$, acusado como un tema de dudosa pertinencia epistemológica, usufructo de una geografía machista (Rose, 1993) en el momento de releer la espacialidad o territorialidad, desde las tangentes de las sexualidades ${ }^{6}$.

Cuando nos referimos a las Geografías de las Sexualidades, es importante resaltar que la sexualidad no se reduce a la descripción de sujetos con preferencias sexuales como figuras discretas (homosexualidad, transexualidad, bisexualidad, intersexualidad, entre otras), sino a una yuxtaposición entre una dimensión individual, social y cultural que elucubra tensiones entre discursos hegemónicos y deseos hegemonizados. Estas normativizaciones encuentran un correlato espacial que emana del estrecho vínculo estatal y político (MесciA, 2006). Las sexualidades como identificaciones aparecen como una instancia condicionada por el contexto entre un plano representacional y experimental ${ }^{7}$, atravesado por pautas culturales. Por ello, quienes se autoproclaman geógrafos de las sexualidades sostienen que se trata de una "subdisciplina fronteriza entre la Geografía Social y Cultural” (BRownE ET ÁL., 2009: 5). Este impulso teórico se dará gracias a la influencia de múltiples miradas críticas, como la feminista, posmoderna y posestructuralista (BRowne ET ÁL., 2009). En este sentido, GarCía RAMÓN (2008) advierte que la geografía ha sido una ciencia apegada a paradigmas tradicionales en el entendimiento de la sociedad y el medio como un conjunto neutro, asexuado y homogéneo. Este esquema no ha reparado sobre las propiedades del espacio que Foucault (1990) ya había subrayado con sus aportes acerca del control social, la anormalidad y las asimetrías que encierran concepciones como la ley y la norma, extrapolables a ciertos espacios de los que emanan consignas sociosexuales. Estas estratifican el espacio "público", cuando se habilitan las acciones de sujetos concebidos como tácitos, en perjuicio y necesidad de omisión sine qua non de las manifestaciones de otros.

\section{Las escalas del estigma}

En un intento por estructurar la breve investigación, tres conceptos son vertebrales para la aprehensión de las espacialidades que permean la "identidad gay"8 (GonzáLEz Pérez, 2014): el estigma, la visibilidad y el contexto. En relación con el primero, GoffmAn fue quien definió al estigma como un atributo desacreditador que cobra operatividad por oposición a distintos rasgos esperables en tanto estereotipados. Este parámetro delimita y normaliza las interacciones sociales, excluyendo a aquellas características (y sujetos) que desencajan con el
5. Ver RAIBAUD (2007), Le genre et le sexe comme objets géographiques.

6. SANtos (2006) argumenta con base en MCNEE (1984), quien habló de la Geografía como institución heterosexista.

7. Esta premisa está inspirada en el enfoque espacial de LEFEBVRE (1998) basado en tres ámbitos (trialéctica) de la producción de la espacialidad de la vida social: las prácticas espaciales (espacios percibidos), las representaciones del espacio (espacios concebidos) y los espacios de representación (espacios vividos).

8. Se sugiere tener presente la diferenciación que puede establecerse entre la homosexualidad y la gaycidad (MECCIA, 2006). Asimismo, el concepto de identidades es garantía de grandes discusiones que no serán abordadas en el presente estudio. 
9. El documento "Violencia contra personas LGBTI" de

la COMISIÓN INTERAMERICANA De DeRECHOS Humanos (CIDH) de la Organización de los Estados Americanos (OEA) la define como la manifestación externa del género de una persona: posturas, forma de vestir, gestos, pautas de lenguaje, el comportamiento $y$ las interacciones sociales.

10. Revisar la apuesta histórica y crítica que elabora VESPUCCI (2017) en Homosexualidades, familia y reivindicaciones.

11. Desde la filosofía, se discute en torno a este concepto, dado que podemos admitir varios matices: nivel de concepto que se asume como valorativamente neutral, el nivel normativo en el caso de que haya oposición moral y el nivel justificativo que surge como un cálculo y no un valor, motivado por el temor en el poder del otro. estereotipo vigorizado. La inferioridad y el rechazo ejercidos afectan a tartamudos, enfermos mentales, drogadictos, prostitutas, alcohólicos y homosexuales, entre otros que cita el autor.

En función del grado de perceptibilidad o visibilidad (Foucautr, 2001) el estigma puede ser desacreditable (un potencial) o desacreditado (un hecho). Por ende, la estigmatización es un efecto que deviene de la visibilidad de un rasgo no deseable según las expectativas de un conjunto panóptico enrolado (dependiente del rol). En relación con esta premisa, Domínguez Bobadilla explica la visibilidad gay de la siguiente manera:

se trata de un conjunto de manifestaciones, expresiones, formas y significados de interacción social que los sujetos de identidad gay deciden esgrimir individual y/o colectivamente como parte integral de su vida. Son prácticas e interrelaciones producto de la expresión consciente o inconsciente de su identidad, tanto para ellos mismos como para su grupo primario, entorno inmediato y/o espacio público (2013: 127).

El número de quienes comparten esta condición sexodiversa influye en la sensación de opresión que la expresión de género ${ }^{9}$ suscita en un espacio. En estos casos, el autoconocimiento no necesariamente robustece una manifestación, ya que lo desacreditable obliga al encubrimiento y/o simulacro goffmaniano, siendo un vuelco solo parcial frente al poder que impone el sistema heterosexista (Rich, 1980).

La visibilización de estas minorías fue paulatina y posibilitada por el sistema capitalista (BLIDon, 2011), de tal manera que, en ocasiones, resulta difícil definirla como una disidencia (SANTOs, 2003), ya que fueron cómodamente absorbidas por una racionalidad pragmática. En otras palabras, el colectivo gay se ha vuelto objetivo estratégico del mercado global que tiene como principal segmento de consumo un estereotipo de varón gay capitalista, que incluye alto poder adquisitivo, hogares unipersonales, preferencias por el arte, la moda, la música y el turismo (economía rosa). Esto repercute en la supresión de otras características que no se homologan a las indicadas, siendo este modelo una trampa de domesticación. En efecto, las experiencias gais terminan legitimando aspectos de la heteronormatividad: el matrimonio gay, que reafirma el concepto de fidelidad ${ }^{10}$; la apariencia física masculina restablece el orden en las relaciones de género; las amigas mujeres, que devuelven al hombre gay su necesario contacto con la mujer heterosexual. Esto asegura un acuerdo implícito de tolerancia ${ }^{11}$, basado en una homosexualidad heterosexualizada (SANTos, 2003). 
Se ha estudiado que las grandes metrópolis, como San Francisco, París, Madrid, Nueva York o Buenos Aires, es decir, ciudades globales, han sido el soporte geográfico de tales visibilidades y disidencias. Es así que las corporalidades y vivencias de los sujetos autodefinidos gais que habitan en geografías ordinarias (BRown, 2008), diferentes del aire cosmopolita de las mencionadas, demuestran no ser escalas propicias para reconocer la diferencia sexual. Pensemos en una localidad del interior de la provincia de Buenos Aires, un ámbito rural o una zona periférica de una ciudad; estos espacios matizan dichas espacialidades, se nivelan a zonas grises cuando del devenir homosexual se trata o, como aduce GonzÁlez Pérez (2014), adquieren una perspectiva de frontera entre dos mundos: el heterosexual y el homosexual. Entonces, ¿qué procesos de visibilidad se dan en otras aglomeraciones, intermedias o pequeñas?, ¿qué poder tiene la representación de ciertos espacios en virtud de las prácticas socio-espaciales del día a día de los sujetos en cuestión? ¿Cuáles son las tácticas (De CerTeAu, 1996) o prácticas furtivas (Marcus, 2011) que emprenderán? Aquí merece atención el contexto.

Las leyes de Matrimonio Igualitario (26.618) y de Identidad de Género (26.743) actúan como garantías de la diversidad frente a su devaluación a lo largo de la historia, pero no son cristalizaciones, sino construcciones lentas y singulares geográficamente de igualdad. Ciertamente, estos "instrumentos vivos" deben ser procesados por una sociedad civil que se presenta heterogénea en sus intereses y que, ante estos rebenques políticos, el armazón cultural de cada grupo social se ve movilizado en lo concerniente a sus acepciones valorativas a priori. Por otro lado, la ley impone que el aceptar ser visto es aceptar ser controlado (BERSANI, 1996), de acuerdo con una escala y, por ejemplo, un acto homoerótico en un espacio público del centro de Buenos Aires puede advertirse como cotidiano; en cambio, en la ciudad de Salta es susceptible de despertar signos claros de "ansiedad social" (Gómez, 2008). Al respecto, el geógrafo Guy Di Meo (1996) en su teorización acerca del espacio social, afirma que el territorio cultural precede el territorio político. Como consecuencia, se impone una contradicción entre la asunción formal, a nivel nacional, de estos cuerpos jurídicos, pero sin una verdadera apropiación en las corporalidades microsociales de ciertas regiones y localidades.

Esto es lo que explica fuertes embates localistas, al no efectuarse una asimilación desde lo representacional ni experimental que suturen la igualdad formal de la igualdad real. Sin dudas, la conquista cúspide de la unión civil entre personas del mismo sexo constituye la 
12. Revisar http://www. sentidog.com/lat/2016/03/ menos-de-la-mitad-demillenials-se-identificanheterosexuales.html.

13. Es sugestiva la clasificación en tres tipos de homofobias de FASSIN (2010) a las que se traduce como "homofobia del pasado" ("de papa"); "homofobia instrumental" ("menaçante") y "homofobia diplomática" (“de bonne compagnie”). Las diferencias radican en los efectos que produce según el uso del lenguaje verbal. las prácticas simbólicas asociadas y los espacios sociales en donde tiene lugar el acto homofóbico.

14. Esta clasificación es resultado del análisis pormenorizado que el autor realiza del caso del Marais en París. adquisición de un derecho, pero no de garantías vivenciales, esto es, las prácticas y manifestaciones de la escala cotidiana.

\section{Presencias, posibilidades y espacios en Bahía Blanca}

"A edades cada vez más tempranas los jóvenes gais son conscientes de su orientación sexual y la experimentan sin mayores complicaciones"12. Este tipo de premisas uniformiza las experiencias individuales y omite el condicionamiento que reproduce determinada procedencia geográfica en la subjetividad de generaciones, que se suponen cada vez más "abiertas" pero residen en contextos "cerrados". Para aportar al debate, Domínguez Bobadilla considera que

la orientación sexual no asigna identidad porque se define sólo en función de su sexualidad o de sus prácticas, mientras que otros manifiestan lo contrario: afirman que en esa diferencia, la de su orientación sexual, radica su esencia como sujetos, su ser, personalidad y estilo de vida. (2013: 133)

Esta última postura contiene refuerzos territoriales, es decir, una conducta proactiva, articuladora y enunciativa. No obstante, el autor enfatiza el peso simbólico que siguen ostentando los estereotipos construidos socialmente alrededor de la identidad de género y la sexualidad como un referente, a veces único, para insertarse socialmente en virtud de no transgredir el orden social y no sufrir desacreditaciones ${ }^{13}$.

Las sexualidades alternativas asumidas en el espacio exterior todavía son percibidas incómodas y vistas como incorrectas. Por consiguiente, se edifican zonas negras de invisibilidad y con ellas la configuración de espacios dudosos, de funcionamiento somero y con fuerte dependencia de los ritmos diurnos-nocturnos. Los antecedentes históricos muestran que el "antro” (centro de reunión nocturno) ha sido el lugar de manifestación e integración del colectivo gay por excelencia: bares, cantinas o discotecas han albergado una confluencia generacional que integra estilos, perfiles y mentalidades (Domínguez Bobadilla, 2013). Por ende, al menos inicialmente, la espacialidad se concentra y limita a la escena nocturna en reductos que promocionaron un "reconocerse sin reconocimiento" (Libson, 2010) por parte del entorno. Bajo esta condición, los procesos de socialización se despliegan en tres tipos de espacios, según LeRoY (2005): los espacios posibles, los espacios del quizás y los espacios imposibles ${ }^{14}$. 
La ciudad de Bahía Blanca se localiza en la región del sudoeste de la provincia de Buenos Aires, es la cabecera del partido homónimo y posee poco más de 300.000 habitantes según el último censo nacional ${ }^{15}$. Asimismo, de acuerdo con el sistema interurbano regional, se posiciona como una ciudad intermedia, siendo su puerto de aguas profundas uno de los factores que confiere gran dinamismo en los intercambios comerciales a nivel nacional e internacional. No obstante, poco se ha dicho de las cuestiones sociales en general, y de las particularidades sexo-genéricas, en particular, que discurren en este espacio.

Dichas coordenadas ofrecen un único espacio de entretenimiento y ocio para el público LGBT, catalogado como espacio posible en función de lo provisto por Leroy: la fiesta Hamsa. Ahora bien, esta posee algunas características en las que detenerse. Los entrevistados han declarado
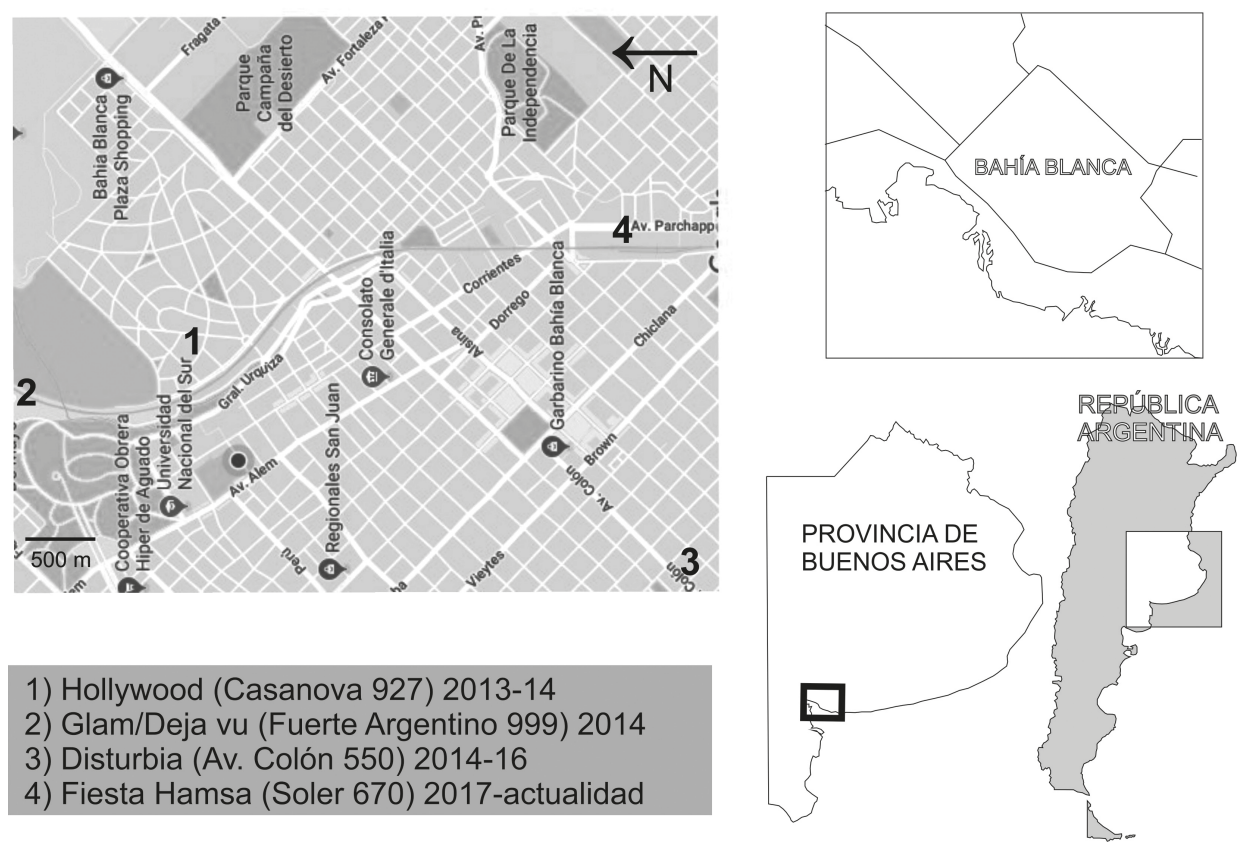

1) Hollywood (Casanova 927) 2013-14

2) Glam/Deja vu (Fuerte Argentino 999) 2014

3) Disturbia (Av. Colón 550) 2014-16

4) Fiesta Hamsa (Soler 670) 2017-actualidad

Cuaderno Urbano. Espacio, Cultura, Sociedad - Vol. 25 - N. ${ }^{\circ} 25$ (Noviembre de 2018)- Pp. 163-183 - ISNN1666-6186
15. Según datos del censo 2010, el partido de Bahía Blanca cuenta con una población de 301.531 habitantes.

Figura 2. Distribución espacio-temporal de espacios de ocio LGBT en Bahía Blanca. Fuente: LARRECHE con base en entrevistas, 2018 
16. Datos extraídos del evento en Facebook: Fiesta Hamsa Bahía Blanca, 2017. la frecuencia de la realización de la fiesta como "insuficiente", opinión que se desprende de la intermitencia tanto en la periodicidad (una vez al mes) como en la rotación del espacio físico, al consumarse en distintas sedes que se alquilan para la ocasión ${ }^{16}$. Quien es la organizadora del evento en los últimos cuatro años expresa: "las fiestas fueron diseminándose en distintos sectores según las predisposiciones de los dueños y el costo del alquiler”. Es así que se ubicaron en múltiples cartografías de la ciudad, algunas ponderadas más que otras.

Los sujetos autodefinidos como gais elaboran una valorización, a manera de código, acerca de los lugares considerados propicios y/o amigables, en orden de exhibir comportamientos que usualmente reprimen en la vía pública, como besarse, tomarse de la mano o de la cintura o, en otros espacios de distensión nocturna, bailar junto a una persona de su mismo sexo. Es indudable que, acorde con ciertas geografías sociales, eso fundamenta la autosegregación (Borvin, 2011) tan discutida desde los cánones de la democracia igualitaria, ya que se conforma un espacio de comodidad más que de libertad, como suscribe Blidon (2011). La comodidad solo abarca las cuatro horas en ese reducto, y consecuentemente desde esas variables espacio-temporales, la fiesta Hamsa se encuentra más próxima a un espacio del quizás que a uno posible. A diferencia de lo que sucede en esta fiesta, las discos para el público heterosexual se mantienen en sus ubicaciones gozando de gran estabilidad, bajo un régimen de propiedad y operando los fines de semana ininterrumpidamente. Más aún, si son exitosas, amplían su estructura edilicia y encauzan una sedimentación en los registros mentales de la población local. Producto del alquiler por día, la alternancia de sedes y falta de regularidad en la organización de la fiesta Hamsa dificultan la identificación de un espacio para el público LGBT que conlleva a un patrón desordenado en la práctica recreativa y la vuelve espontánea; un azar que puede suponer un impacto diferencial en función del número y diversidad de concurrentes para socializar: "ver caras nuevas para hacer de la noche algo más interesante”; con el defecto de nunca adoptar la forma de plan B.

"Salir del clóset" es apenas el comienzo de una serie de salidas que estos sujetos enfrentarán en la vida cotidiana durante su existencia (DomínGuez y De LA CRUZ, 2013). Esta exogamia, entendida como la conexión entre el espacio privado y el público, comporta una desconexión al evaluarse cuidados y simulacros que reafirman la extensión de la fase privada de la práctica socioafectiva: "nunca me sentí cómodo dándole la mano a mi pareja", "no estoy preparado para besar a mi novio en la calle". Asimismo, las posibilidades espaciales 
se bifurcan según el rango etario y las experiencias acumuladas ${ }^{17}$ para "salir del armario al barrio" (GARCíA Escalona, 2000). Ser, parecer, decir, callar, aparentar, asumir, dar a entender son siempre los ejes de una visibilidad aparente, reflexiona Domínguez BoBadiLla (2013). En este sentido, muchas veces, la gestión de la identidad (Blanco, 2000) no se negocia en los marcos de la visibilidad. Según lo recabado, los bahienses autoadscriptos gais construyen sus lazos con el afuera precariamente, apoyados en tres tácticas ${ }^{18}$ principales que versan sobre espacios imposibles: la clandestinidad, el exilio y la virtualidad.

Estar ocultos es la condición en la configuración del primero. TERUKINA (s. f.) reflexiona que el ingreso de estos espacios para el encuentro es solo accesible para quienes los conocen por el "boca en boca". Se presentan camuflados, ya que físicamente coinciden con parques y plazas, pero, en instancias de la noche y vaciados de transeúntes, adquieren una función sociosexual ${ }^{19}$. En este caso, las interacciones se vertebran en torno a un secreto fundante (Pecheny, 2001) que invita a un juego de miradas más que a un intercambio verbal.

Los entrevistados hablan de "sociedad cerrada", "gente careta", "ciudad chata" cuando personalizan su ciudad, y, en muchos de sus relatos, enaltecen la posición que ocupa Buenos Aires como válvula de escape y anclaje espacial, dotada de múltiples espacios de ocio y anonimato y menor distancia social, que permiten que se reduzcan los efectos de rareza que acompañan su visibilidad en Bahía Blanca. Cuando se alude a reducir, no se privilegia la desaparición de instancias homofóbicas, dado que como suscribe ERIBón (1999) los insultos forman una parte clave en la totalidad de las experiencias homosexuales.

La geografía define y explica los conceptos de nomadismo y migración, que se vinculan intrínsecamente al desplazamiento. Admitiendo su discusión, se prefiere optar por el exilio como concepto, ya que se comprende que los sujetos dan cuenta de que es una huida forzada. En su concepción tradicional, el exilio responde una migración, es decir, supone un cambio definitivo en la gravitación del espacio de vida de quien lo lidera, por motivos principalmente políticos. Siguiendo este aspecto, Brown (2008) arguye que las migraciones gay entre las zonas rurales, suburbanas y urbanas son, a largo plazo, unidireccionales, y siempre dan como resultado que las vidas homosexuales se lleven a cabo en el centro de la ciudad. Este autor resalta el papel de hogar que revisten los centros gay metropolitanos, que juegan un papel relacional de gran repercusión emocional y social. Si se establece que la subjetividad sexual reporta un posicionamiento político y que, con proyección a un futuro,
17. Se pudo registrar que el atributo de género también comporta un rasgo distintivo en la expresividad de la sexualidad: "se ven más lesbianas por la calle, se animan más".

\section{De CERTEAU llama} táctica a un cálculo que no puede contar con un lugar propio, que se insinúa fragmentariamente sin tomarlo en su totalidad. No dispone de una base para capitalizar sus ventajas, preparar sus expansiones $y$ asegurar una independencia en relación con las circunstancias (1996: L).

19. RAPISARDI Y MODARELLI (2001) y BAZÁN (2006) han analizado la sociología de los baños públicos porteños durante la última dictadura. En ciudades turísticas como Mar del Plata, las oficinas de turismo solían ofrecer planos (los Gmaps) en donde se podía obtener información de espacios LGBT del circuito oficial y el de "yire". 
20. Para profundizar sobre el tema, se recomienda LEAL GuerRero (2011) La Pampa y el Chat.

21. Ver MARENTES; PALUMBo y Boy, (2016) "Me clavó el visto": Los jóvenes y las esperas en el amor a partir de las nuevas tecnologías.

22. Expresión extraída de https://www.pagina12.com. ar/diario/suplementos/soy/14373-2016-01-29.html. las residencias mutarán de lugar, es al menos permisible el término exilio. A lo largo de las conversaciones, los informantes hablaron de amistades que se habían ido a estudiar o, una vez recibidos, se había ido "a probar suerte" en Buenos Aires, alegando que "en Bahía no hay movida gay, no pasa nada”. Son casos de jóvenes, entre veinte y treinta años, que incluso han salido del clóset una vez que cambiaron su domicilio. Asimismo, el proyecto de exilio ha sido reiterado en las protagonistas de las entrevistas.

Por último, la virtualidad parece ser el canal más inmediato y extendido en torno a los más jóvenes, a partir del uso de aplicaciones para conocer personas que pueden descargar desde sus teléfonos móviles: Grindr, Badoo, Tinder, como las principales mencionadas. Mediante esta modalidad, son cuestionables tanto el outing como la experiencia de los espacios reales (tradicionales para los estudios en geografía), dado que, a diferencia de las tácticas anteriores, esta no requiere una visibilidad in situ del sujeto. Para el caso de Bahía Blanca, tampoco reviste una visibilidad siquiera virtual, ya que "dominan los perfiles sin fotos", "ahí nadie da la cara", exclaman nuestros informantes. A grandes rasgos, no existe certeza de la identidad de quien está detrás de una pantalla, auspiciando una distorsión o hasta una falsificación intencionada de quien usa imágenes falsas: "mienten", "te llevas cada chasco" ${ }^{20}$. Sin embargo, no deja de ser un repositorio del deseo que brinda no solo facilidad, supeditada a las maniobras táctiles, "no tengo que salir de casa", sino conveniencia: "me ahorro viajar a capital". Asimismo, estas sociabilidades oponen un redimensionamiento geográfico interesante: la vida offline y online (Morcillo, 2017).

A través de las entrevistas y el análisis de imágenes (figura 3) aparecen diálogos que fortalecen la idea de un clóset virtual: "si querés foto, pasá antes de pedir"; "si vos me hablaste primero, tenés que mandar vos”, "yo me pongo en discreto (en relación al casillero tribus), como la mayoría de esta ciudad". Esta ida y vuelta intrincada produce estrés y malestar en la dilatación del encuentro ${ }^{21}$, que sólo asegura la sucesión de los "bit vip”22. Finalmente, el sentimiento es frustrante: "qué difícil es quedar con alguien acá en Bahía".

Con estas espacialidades tendientes a la imposibilidad queda expuesto que no importa tanto que los sujetos tengan una sexualidad diferente de la heterosexual y la ejerzan; lo que más provoca el pánico moral es su muestra pública, pues ello implica asignarle un sitio dentro del universo sexual (List, 2009: 152). 


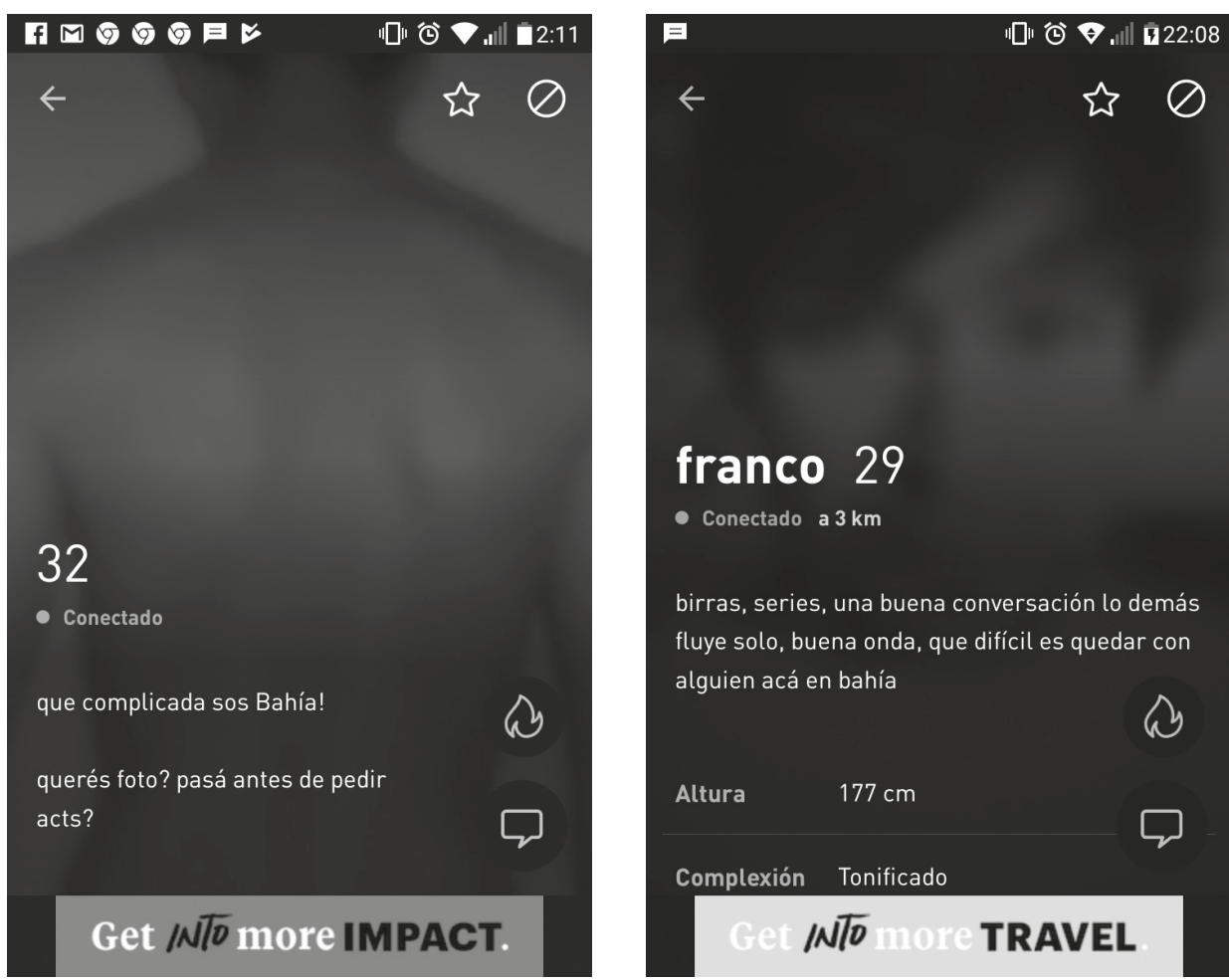

Figura 3. Perfiles virtuales en la ciudad de Bahía Blanca. FUente: LARRECHE, extraídas del sitio de citas gay Grindr, 2018

En el caso de Bahía Blanca algunos sucesos ponen en foco el delgado límite entre lo que los "normales" acusan de exhibicionismo y lo que los estigmatizados defienden como expresión de la libertad a través gestos que acrecientan la sospecha del contrarreivindicador en términos de goffmanianos ${ }^{23}$. Durante 2014 un acontecimiento de discriminación contra una pareja de lesbianas expuso la marginalización que todavía sufren ciertos ciudadanos, quienes debieron abandonar el lugar como consecuencia de demostrarse afecto. Si recapitulamos lo

23. Ver http://labrujula24. com/noticias/2014/6443_Unapareja-de-lesbianas-afirmaque-las-echaron-de-un-cafepor-besarse. 
24. Héctor Gay, intendente de Bahía Blanca, sobre el matrimonio igualitario. Fuente: Diario La Nueva Provincia, 23/04/2016. expuesto, las sexualidades tensionan una dimensión subjetiva, social y estatal, por lo que las declaraciones defendidas por el actual intendente de la ciudad siguen fagocitando una división sociosexual jerarquizada: "creo que hay un orden natural de las cosas"24.

\section{Lo personal no siempre es político: cambios lentos en la intermedia Bahía Blanca}

A partir de las iniciativas legales mencionadas, se materializa un pluralismo en lo concerniente a los planes de vida de los miembros de la sociedad y sus formatos familiares. A contrapelo, García CANCLINI (1989) expresa lo siguiente:

a pesar de la irrupción, y a veces imposición, de los discursos de la modernidad en las sociedades tradicionales, éstas construyen mecanismos para incorporar, adaptar y fusionar dichas representaciones y significados a sus aconteceres cotidianos, en los que se aprecia una negociación que resguarda a la vez que transforma de manera gradual los contextos sociales. (1989: 36)

Este reducto consuetudinario apunta a los entornos de socialización primaria y secundaria (BERGER y LuCKMANN, 1968), como la familia y la escuela, donde pueden predominar aún marcos interpretativos conservadores, especialmente en América Latina, donde los discursos religiosos han condicionado fuertemente la esfera política y social.

En una ciudad como Bahía Blanca puede evidenciarse un paralelismo con el caso de Aguascalientes (Domínguez Bobadilla, 2013), donde la espacialidad gay responde al panóptico del círculo social que, en una ciudad pequeña, tiene el carácter de ser muy próximo; "todo el mundo se conoce", "el ambiente es muy chico", afirman los entrevistados. La paranoia que regula esta circunstancia decrece en la medida en que las posibilidades de encuentro y coincidencia con estos receptores sociales más directos (familia y colegas) están fuera del horizonte de visibilidad. Es por ello que se prefieren deliberadamente espacios tranquilos, ya sea muy alejados del corazón urbano e inclusive escondidos, como opciones de interacción.

El imaginario de Bahía Blanca "se ha construido en la tensión continua entre el deseo de coherencia y continuidad y un deseo de dinamismo y modernidad" (FAcchinetTi LuigGi, 1996: 225). Esta autora establece que la ciudad se presenta a sí misma como una ciudad homogénea y un modelo ideal de convivencia, a pesar de que vista "desde dentro", se presenta interpelada 
por múltiples tensiones (FAcchinetTI LuIGGI, 1996). Revertir ese "no ser" de la sociedad bahiense que afecta el espacio vivido y el sentido de pertenencia de determinados sujetos es una tarea ardua y de decantación de una conciencia colectiva. El proceso de transformación que vive la ciudad debe partir de la negociación que estos sujetos desencadenan (y aceleran) cuando se muestran públicamente, remarcando que el espacio público es, per se, heterogéneo y diverso. La emancipación en las consecutivas escalas es contingente de esta artesanía política.

En el estudio de GonzÁlez Pérez (2014) se plantea un gradual empoderamiento de la comunidad gay:

los homosexuales hasta antes de los años cincuenta únicamente contaban con una identidad virtual formada con estigmas, por esta razón en los años sesenta los homosexuales se autoproclamaron como gais, lo que sirvió no sólo para construirse un proyecto político sino también romper con una serie de taxonomías peyorativas que les habían sido imputadas. Con estas acciones reivindicativas, los gais dejaron ver un espacio social construido por ellos mismos. (2001: 108)

La percepción desalentadora de la ciudad por parte de estos bahienses en el afán de deslizarse por itinerarios anónimos y zonas grises difumina el compromiso político que puede ser clave para un mejor horizonte. Existen pocas organizaciones LGBT con continuidad hacia adentro de su localidad: "no me interesa" "nunca participé de marchas, es un quemo" son motivos de algunos. Se entiende que la asunción de esta posición indiferente termina por ser contraproducente para su capital espacial. Asimismo, los pocos que participan de marchas de diversidad son vistos con vergüenza desde sus pares. Queda planteada la controversia, ya que, por un lado, los entrevistados expresan el deseo de multiplicar sus espacios vividos, hoy en déficit, pero, por el otro, esperan que esta proliferación sea producto de la inercia, a costa de un nulo pacto personal y territorial. En otras palabras: se translucida que la simulación sigue eclipsando la disidencia.

Las ciudades intermedias, como Bahía Blanca, son urbes que crean puentes de conexión importantes entre zonas rurales y urbanas, siendo para la población la oportunidad de acceder a mayor número de ventajas: educación en todos los niveles, hospitales de alta complejidad, administración bancaria, paso hacia otros centros regionales, mayores posibilidades de empleo, entre otros. La condición de intermedia remite a una función nodalidad en una red urbana. No obstante, se sospecha que la cualidad de intermedia anula el aporte 
25. Variable incorporada en la planilla del último CENSO realizado en 2010 desde los procesos sociales y sostiene la rigidez de un concepto empleado extensivamente en clave productiva-distributiva-consumista. En este sentido, en el marco de la llamada segunda transición demográfica (STD), es propicio incorporar un análisis social. Este fenómeno, apreciado en los países desarrollados en un principio, señala cambios que se avecinan en materia de nupcialidad y fecundidad, en que las actuales cuestiones de género y sexualidad guardan una especial relación en la emergencia de distintos modelos de familia y composición de los hogares, entre ellos los que responden a uniones entre personas del mismo sexo (homoparentales) ${ }^{25}$, que afectan de forma dispar a las ciudades.

Como registró Ribas (2008) en sus investigaciones, la conformación de un imaginario espacial multifocal a partir de la construcción del nudo ferro-portuario en la década del ochenta del siglo XIX en Bahía Blanca afianzó la ideología del progreso, rumbo que impera hasta la actualidad. El fuerte peso de aspectos de la historia reciente, como el establecimiento de la base naval de la armada en Puerto Belgrano (cercana a la ciudad de Punta Alta, a 28 km de Bahía Blanca) y los episodios de la última dictadura militar en complicidad con la iglesia católica y otros actores que, tradicionalmente, han sido funcionales al control y coerción subtalterna pueden ser aproximaciones válidas en la búsqueda de los orígenes de las representaciones que encierran a la sociedad de Bahía Blanca, desde el ángulo de las minorías. Por último, y para despuntar un horizonte de optimismo, la ciudad constituye un núcleo regional (puerta hacia el sur y norte del país) que alberga residentes de otras localidades, principalmente por su función universitaria y perfil empresarial. Estos aspectos pueden ser importantes para un vuelco total en estos asuntos.

\section{A modo de cierre}

La geografía de las sexualidades representa un campo fértil y de gran potencialidad en las relecturas de las intersecciones entre geografía social, geografía cultural y geografía urbana. Desde una impronta situacional, se ha reparado en comprender e interiorizar los sentidos de lugar que sujetos autodefinidos gais trazan en la ciudad intermedia de Bahía Blanca. Para ello, primeramente, se realizó una búsqueda de nuevos horizontes teóricos que permitan comprender, a través de conceptos instrumentales, la realidad social particular aparejada a las sexualidades en discusión. Tener en cuenta la importancia de nociones planteadas como la estigmatización, las expresiones de género y el placar social demuestran que estas versan sobre constructos socioespaciales. 
Se constató la fuerza de las representaciones que etiquetan a Bahía Blanca como "ciudad chata”, y su significado como filtro de las vivencias de estos grupos que, como fuente de compensación, se animan a delinear prácticas serpenteantes en pos de recuperar su capital espacial (Herin, 2006) de alcance local y nacional. Se dilucida que las costumbres de ciertos espacios dominan por sobre el poder de las leyes alusivas al reconocimiento de la diversidad, que se diluyen. De esta manera, las relaciones sociales de alcance público quedan atravesadas por una "antropología de la vergüenza" (ЕRiBON, 2015), que guarda estrecha asociación con la comunidad que habitan, en menoscabo de su experiencia en el espacio desde lo representacional-experimental.

El sistema patriarcal y las pautas de normalización que evoca irrumpen en el espacio, ofreciendo ámbitos habilitadores sobre la base de la dicotomía heterosexual-homosexual; visible-invisible, con su desprendimiento geográfico: Buenos Aires-interior. En efecto, se demostró que estos individuos plantean la búsqueda de nuevas espacialidades que parecen nunca solidificarse para sus prácticas socioafectivas en su espacio inmediato, a través de la coexistencia de mecanismos antiguos (“yire”) y actuales (Grindr). Los sujetos autodefinidos gais, en esta área de estudio, aún siguen replegados a lo que ButLer (2005) denomina un modo ontológico en suspensión.

Por otro lado, se expuso que resulta dificultosa, para los sujetos observados, la apropiación de tales afecciones en un conjunto de prácticas positivas que gestionen visibilidad e inclusión, es decir, una territorialidad efectiva y militante en su lugar natal. Por ende, los espacios sociales de cada grupo se definen con suma dependencia del contexto espacial. En efecto, la geografía auspicia de interlocutora de estas experiencias situadas, siendo un insumo cardinal en la federalización de estos asuntos.

\section{Bibliografía}

BELL, David y VALENTINE, Gill (1995) Mapping desire: Geographies of sexualities. Routledge, Londres.

BERGER, Peter y LUCKMANN, Thomas (1986) La construcción social de la realidad. Amorrortu, Buenos Aires.

BERSANI, Leo (1996) Homos. Harvard University Press, Londres. 
BINNIE, Jon (1997). “Coming out of Geography: towards a queer epistemology?” En: Environment and Planning D: Society and Space, vol. 15, núm. 2, 223-237.

BLANCO, Rafael (2014) Universidad íntima y sexualidades públicas: la gestión de la identidad en la experiencia estudiantil. Miño y Dávila.

BLIDON, Marianne (2011). "En quête de reconnaissance. La justice spatiale à l'épreuve de l'hétéronormativité. Justice spatiale - spatial justice”. Université Paris Ouest Nanterre La Défense, Laboratoire Mosaïques, Genre, identités sexuelles et justice spatiale, 3. Disponible en http://www.jssj.org/article/en-quete-de-reconnaissance-la-justice-spatiale-a-lepreuve-delheteronormativite/.

BOIVIN, Renaud (2011). "De la ambigüedad del clóset a la cultura del gueto gay: género y homosexualidad en París, Madrid y México”. En La Ventana, Revista de estudios de género, vol. 4, núm. 34, 146-190.

BROWN, Gavin (2001). "Listening to queer maps of the city: Gay men's narratives of pleasure and danger in London's East End”. En Oral History, 48-61.

BROWN, Gavin (2008). "Urban (homo) sexualities: Ordinary cities and ordinary sexualities". En Geography compass, vol. 2, núm. 4, 1215-1231.

BROWNE, Kath; LIM, Jason y BROWN, Gavin (2009) Geographies of sexualities: theory, practices and politics. Ashgate Publishing, Ltd.

BUTLER, Judith (2005) Humain, inhumain. Le travail critique des normes. Éditions Amsterdam, Paris.

CASTELLS, Manuel (1979) La cuestión urbana. Siglo Veintiuno, España.

COMISIÓN INTERAMERICANA DE DERECHOS HUMANOS (2015). "Violencia contra personas LGBTI en América". Documento de la CIDH, Washington.

DE CERTEAU, Michel (1996) La invención de lo cotidiano. Artes del hacer. Universidad Iberoamericana, México.

DOMÍNGUES BOBADILLA, Juan de la Cruz (2013). "Visibilidad gay y espacio público en la capital de Aguascalientes: romper para entrar o entrar para romper”. En Desacatos, núm. 41, 123-138.

DI MÉO, Guy (1996) Les territoires du quotidien. L’Harmattan, Paris.

ERIBÓN, Didier (2005) Regreso a Reims. Libros del Zorzal, Buenos Aires.

ETTORRE, Elizabeth (1978) "Women, urban social movements and the lesbian ghetto". En: International Journal of Urban and Regional Research, vol. 2, núm.1-4, 499-520.

FACCHINETTI LUIGGI, Graciela (1996) Bahía Blanca: Cultura, identidad, región. EdiUNS, Bahía Blanca. 
FASSIN,Éric (2010). "Les trois figures de l’homophobie”. Rapport annuel SOS homophobie, Paris. FOUCAULT, Michel (1990) Vigilar y castigar: nacimiento de la prisión. Siglo Veintiuno, México.

FOUCAULT, Michel (2001) Los anormales. Ediciones Akal.

GARCÍA CANCLINI, Néstor (1989) Culturas híbridas: estrategias para entrar y salir de la modernidad. México.

GARCÍA RAMÓN, María Dolors (2008). “¿Espacios asexuados o masculinidades y feminidades espaciales?: hacia una geografía del género”. En SÉMATA, Ciencias Sociais e Humanidades, núm. 20, 25-51.

GOFFMAN, Erving (1970) Estigma: la identidad deteriorada. Amorrortu, Buenos Aires.

GÓMEZ, María Mercedes (2008). “Violencia por Prejuicio”. En: Motta, Cristina y Sáes, Macarena. La Mirada de los Jueces: Sexualidades diversas en la jurisprudencia latinoamericana. Siglo del Hombre, Bogotá, 185-186.

GONZÁLEZ PÉREZ, César (2014). "La identidad gay: una identidad en tensión. Una forma para comprender el mundo de los homosexuales”. En Desacatos, núm. 6, 97-110.

HERIN, Robert (2006). "Por una geografía social, crítica y comprometida". En Scripta Nova: revista electrónica de geografía y ciencias sociales, núm. 10.

HUBBARD, Phil (1999). "Sex and the City". En Geographies of.

JAURAND, Emmanuel (2011). “Territorialités gays”. En Espaces e societes, núm. 32, 7-13.

LAURIA, Mickey y KNOPP, Lawrence (1985). "Toward an analysis of the role of gay communities in the urban renaissance”. En Urban geography, vol. 6, núm. 2, 152-169.

LEAL GUERRERO, Sigfredo (2011) La Pampa y el Chat. Aphrodisia, imagen e identidad entre hombres. Antropofagia.

LEFEBVRE, Henri (1991) The production of space. Blackwell, Oxford.

LEROY, Stephane (2005). "Le Paris gay. Éléments pour une géographie de l'homosexualité". En Annales de Géographie, núm. 646, 579-601.

LIBSON, Micaela (2010). "Hay tantas maneras de no ser. Derechos lésbicos-gais y reconocimiento de los contextos familiares”. En: Sexualidad, Salud y Sociedad-Revista Latinoamericana, núm. 6.

LINDÓN, Alicia y HIERNAUX, Daniel (2010). Los giros de la geografía humana. Desafíos y horizontes. Anthropos, México.

LIST, Mauricio (2009) Hablo por mi diferencia. De la identidad gay al reconocimiento de lo queer. Eón Ediciones, México. 
MARCÚS, Juliana (2011). "La ciudad múltiple. Percepciones, usos y apropiaciones del espacio urbano”. En Margulis, Mario, Urresti, Marcelo, Lewin, Hugo y otros. Las tramas del presente desde la perspectiva de la sociología de la cultura. Biblós, Buenos Aires, 137-150.

MARENTES, Maximiliano; PALUMBO, Mariana y BOY, Martín (2016). "Me clavó el visto: Los jóvenes y las esperas en el amor a partir de las nuevas tecnologías”. En Astrolabio, núm. 17, 307-330. Disponible en: <https://revistas.unc.edu.ar/index.php/astrolabio/article/ view/13376>.

MECCIA, Ernesto (2006) La cuestión gay: un enfoque sociológico. Gran Aldea Editores. NOGUÉ, Joan y ROMERO, Joan (2006) Las otras geografías. Tirant lo blanch, Valencia. PECHENY, Mario (2001). "De la no-discriminación al reconocimiento social. Un análisis de la evolución de las demandas políticas de las minorías sexuales en América Latina”. Ponencia presentada al XXIII Congreso de la Latin American Association, Washington DC.

RAIBAUD, Yves (2007). "Le genre et le sexe comme objets géographiques“. En: Sexe de l'espace, sexe dansl'espace, núm. 2, 97-105.

RIBAS, Diana (2008). "Del fuerte a la ciudad moderna: imagen y auto-imagen de Bahía Blanca”. Tesis Doctoral. Programa de Postgrado en Historia, Departamento de Humanidades, Universidad Nacional del Sur, Argentina.

RICH, Adrienne (1980). "Compulsory heterosexuality and lesbian existence”. En: Signs, Journal of women in culture and society, vol. 5, núm. 4, 631-660.

ROSE, Gillian (1993) Feminism and geography: the limits of geographical knowledge. Polity Press, Cambridge.

SABSAY, Leticia (2011) Fronteras sexuales. Espacio urbano, cuerpos y ciudadanía. Paidós, Buenos Aires.

SANTOS, Xosé (2003). “Espacios disidentes en los procesos de ordenación territorial”. En Revista Pegada, vol. 4 núm. 2.

SANTOS, Xosé (2016). "Estudis de gènere i sexualitat a Espanya a través de les revistes de geografia (1990-2014)”. En Documents d'anàlisi geogràfica, vol. 62, núm. 2, 427-448.

TERUKINA, Kenji (s. f.) Heterotopología de los emplazamientos del placer homo erótico en Lima.

THEUMER, Emmanuel (29 de enero de 2016) Bit vip. Suplemento Soy, Página 12. Recuperado de https://www.pagina12.com.ar/diario/suplementos/soy/1-4373-2016-01-29.html.

VESPUCCI, Guido (2017) Homosexualidad, familia y reivindicaciones: De la liberación sexual al matrimonio igualitario. UNSAM Edita, San Martín. 


\section{Otras fuentes citadas}

Una pareja de lesbianas afirma que las echaron de un café por besarse (31 de marzo de 2014). La Brújula 24. Recuperado de http://labrujula24.com/noticias/2014/6443_Una-parejade-lesbianas-afirma-que-las-echaron-de-un-cafe-por-besarse.

Gay sobre matrimonio igualitario: "Creo que hay un orden natural de las cosas" (26 de abril de 2016). La Nueva Provincia. Recuperado de http://www.lanueva.com/nota/2016-4-23-1459-0-gay-sobre-matrimonio-igualitario-creo-que-hay-un-orden-natural-de-las-cosas.

Menos de la mitad de millenials se identifican heterosexuales (15 de marzo de 2016). Portal Sentido G. Recuperado de http://www.sentidog.com/lat/2016/03/menos-de-la-mitad-de-millenials-se-identifican-heterosexuales.html. 